\title{
Contraception in chronic kidney disease: a best practice position statement by the Kidney and Pregnancy Group of the Italian Society of Nephrology
}

\author{
Rossella Attini ${ }^{1}$. Gianfranca Cabiddu ${ }^{2}$. Benedetta Montersino ${ }^{1}$ - Linda Gammaro ${ }^{3}$. Giuseppe Gernone ${ }^{4}$. \\ Gabriella Moroni ${ }^{5}$. Domenico Santoro ${ }^{6}$. Donatella Spotti ${ }^{7}$. Bianca Masturzo ${ }^{1}$ - Isabella Bianca Gazzani ${ }^{1}$. \\ Guido Menato ${ }^{1} \cdot$ Valentina Donvito $^{8} \cdot$ Anna Maria Paoletti $^{9} \cdot$ Giorgina Barbara Piccoli ${ }^{10,11}$
}

Received: 24 November 2019 / Accepted: 25 February 2020 / Published online: 12 March 2020

(c) The Author(s) 2020

\begin{abstract}
Even though fertility is reduced, conception and delivery are possible in all stages of CKD. While successful planned pregnancies are increasing, an unwanted pregnancy may have long-lasting deleterious effects, hence the importance of birth control, an issue often disregarded in clinical practice. The evidence summarized in this position statement is mainly derived from the overall population, or other patient categories, in the lack of guidelines specifically addressed to CKD. Oestroprogestagents can be used in early, non-proteinuric CKD, excluding SLE and immunologic disorders, at high risk of thromboembolism and hypertension. Conversely, progestin only is generally safe and its main side effect is intramestrual spotting. Non-medicated intrauterine devices are a good alternative; their use needs to be carefully evaluated in patients at a high risk of pelvic infection, even though the degree of risk remains controversial. Barrier methods, relatively efficacious when correctly used, have few risks, and condoms are the only contraceptives that protect against sexually transmitted diseases. Surgical sterilization is rarely used also because of the risks surgery involves; it is not definitely contraindicated, and may be considered in selected cases. Emergency contraception with high-dose progestins or intrauterine devices is not contraindicated but should be avoided whenever possible, even if far preferable to abortion. Surgical abortion is invasive, but experience with medical abortion in CKD is still limited, especially in the late stages of the disease. In summary, personalized contraception is feasible, safe and should be offered to all CKD women of childbearing age who do not want to get pregnant.
\end{abstract}

Keywords Contraception · Birth control $\cdot$ Chronic kidney disease $\cdot$ Dialysis $\cdot$ Kidney transplantation $\cdot$ Abortion $\cdot$ Hormonal contraceptives $\cdot$ Intrauterine devices $\cdot$ Barrier methods $\cdot$ Emergency contraception

This article is part of the topical collection on Obstetric

Nephrology.

Giorgina Barbara Piccoli

gbpiccoli@yahoo.it

1 Department of Obstetrics and Gynecology, Città della Salute e della Scienza, Ospedale Sant'Anna, Turin, Italy

2 Nephrology, Azienda Ospedaliera Brotzu, Cagliari, Italy

3 Nephrology Ospedale Fracastoro San Bonifacio, San Bonifacio, Italy

4 Nephrology, Ospedale Santa Maria Degli Angeli, Putignano, Italy

5 Nephrology, Fondazione Ca' Granda Ospedale Maggiore, Milan, Italy

6 Nephrology and Dialysis, Azienda Ospedaliera Universitaria "G. Martino", Messina, Italy
7 Nephrology and Dialysis, IRCCS Ospedale San Raffaele, Milan, Italy

8 Department of Internal Medicine, Ospedale Sant'Anna, Città della Salute e della Scienza, Turin, Italy

9 Department of Surgical Sciences, Obstetrics and Gynecology, University Hospital of Cagliari, Cagliari, Italy

10 Department of Clinical and Biological Sciences, Università di Torino, Turin, Italy

11 Nephrology and Dialysis, Centre Hospitalier Le Mans, Le Mans, France 


\section{Introduction}

Chronic kidney disease (CKD) is usually cited as a cause of reduced fertility, but in fact this simplistic assumption is probably true only for the last stages of the disease, or for some immunologic diseases, of which systemic lupus erythematosus (SLE) can be considered the prototype [1-4].

Almost paradoxically, we have more information on fertility and pregnancy rates in the late stages of kidney disease, mainly because CKD is known and acknowledged, than in the early CKD stages, in which a significant number of women, perhaps even the majority, do not realize they are affected by CKD, or do not consider that this is relevant in determining pregnancy outcomes [1,5-7].

While several recent studies have been addressed to women with CKD and their desire, still too often frustrated, to give birth, contraception is not a part of the routine work-up for CKD patients, notwithstanding the fact that, albeit with lower rates, pregnancy is possible in all CKD stages, including transplantation and dialysis $[1,2$, 8-12].

It is in particular in the late CKD stages that the widespread idea that fertility is sharply reduced may cause doctors to overlook counselling on contraception, with potentially devastating clinical and psychological effects. Careful planning of pregnancy is vitally important in all disease stages, to avoid complications for mother (for example in the case of active immunologic diseases) and foetus (for example exposure to potentially teratogenic drugs) [13-16].

Some recent reviews have addressed the issue of contraception in CKD; they all acknowledge the lack of detailed, specific evidence deriving from primary studies on CKD women [17-21]. The high heterogeneity of CKD stages, type of disease and treatment is one of the reasons for this lack of evidence or of the use of low-quality evidence, even in the fields most often studied (kidney transplantation, lupus nephropathy and diabetic nephropathy) [20-23].

With this in mind, the Italian Society of Nephrology's Project Group on Kidney and Pregnancy has undertaken the preparation of the present best practice statement. We will try to summarize the available evidence and provide answers to open questions on contraception in CKD integrating the currently available "best practice" statements on pregnancy in CKD, dialysis, kidney transplantation and follow-up after preeclampsia [24-27].

Our review will first discuss the main modes of contraception available for the general population, and then try to contextualize them in the various stages of $\mathrm{CKD}$, in dialysis and after kidney transplantation, with particular regard to the potential interaction between contraceptives and the pharmacologic treatments most commonly used in CKD.

\section{World Health Organization (WHO) criteria for election of contraception}

Analogously to its classification of drug teratogenicity, the World Health Organization (WHO) provides a general score for supporting contraceptive eligibility in different diseases (Table 1) [28]. The safety of every contraceptive is classified in one of four categories: in categories 1-2 the use of the contraceptives is with no or minimal restriction, in categories 3 and 4, WHO advises avoidance, (the strength of recommendations varies in and motivated exceptions are proposed in category 3 ).

The evidence on which WHO criteria were based came from studies on a wide range of diseases and conditions, among them diabetes, hypertension, SLE and kidney transplantation. Chronic kidney disease was, however, not included.

WHO's Medical Eligibility Criteria (MEC) for contraception are based on two complementary considerations regarding safety: first, the effect the contraceptive has on the disease (worsening or increasing risk); second, the effect the disease has on the efficacy of the contraceptive method.

WHO's most recent classification considers the following contraceptive methods:

- Combined hormonal contraceptives (CHC)

- low dose ( $\leq 35 \mathrm{mcg}$ Ethinyl Estradiol) combined oral contraceptives (COCs).

- Combined patch (P).

- Combined vaginal rings (CVR).

Table 1 Medical Eligibility Criteria (MEC) for contraceptive use (WHO 2015) [28]

\begin{tabular}{ll}
\hline MEC categories for contraceptive eligibility \\
\hline 1 & A condition for which there is no restriction for the use of the contraceptive method \\
2 & A condition where the advantages of using the method generally outweigh the theoretical or proven risks \\
3 & A condition where the theoretical or proven risks usually outweigh the advantages of using the method \\
4 & A condition which represents an unacceptable health risk if the contraceptive method is used
\end{tabular}

MEC Medical Eligibility Criteria, WHO World Health Organization 
- Combined injectable contraceptives (CICs) *.

- Progestin-only pills (POPs).

- Depot-medroxyprogesterone acetate (DMPA)*.

- Norethisterone enanthate (NET-EN)*.

- Levonorgestrel (LNG)* and Etonogestrel (ETG) implants.

- Emergency contraceptive pills (ECPs).

- Copper-bearing intrauterine devices (Cu-IUDs).

- Levonorgestrel-releasing IUDs (LNG-IUDs).

- Copper-IUDs for emergency contraception (E-IUD).

- Progesterone-releasing vaginal rings (PVR)*.

- Barrier methods (BARR).

- Fertility awareness-based methods (FAB).

- Lactational amenorrhoea method (LAM).

- Coitus interruptus (CI).

- Female and male sterilization (STER).

* Not available in Italy.

In our review we use WHO's categories of contraceptive methods and their specific Medical Eligibility Criteria (MEC). Obviously, as is emphasized in the MEC, counselling must be personalized and consider individual characteristics and risk factors; those generally listed include age, breastfeeding status, dyslipidaemia, severe cardiovascular disease, migraine, severe liver disease, concomitant therapies and body mass index. Kidney diseases are not specifically considered, hence the need for the present best practice statement.

\section{Efficacy of contraceptive methods}

The efficacy of a contraceptive method is conventionally measured by the Pearl Index, i.e. the number of pregnancies in 100 women using the method for 1 year (1300 periods). The lower the number, the more effective the method is. It should be noted that to some extent the Pearl Index depends on the user population's characteristics, training in correct use of the method and the fertility of the couples included.

A recent US review proposes a classification of contraceptive effectiveness stratified for "optimal use" or "typical use" (taking inaccuracies into account); it also analyses adherence to methods after 1 year of use. Apart from surgical methods (which are obviously definitive), compliance is high for implants and IUDs, which can remain in place for 3-5 years, but adherence to combined hormonal contraceptives was as low as $67 \%$. Barrier methods are quite effective with "perfect" use, but typical use produces a high percentage of unintended pregnancies; the same applies to withdrawal and ovulation methods (Table 2) [29].

There are also differences between countries regarding availability and choice of contraceptives. For example, in
Table 2 Percentage of failure of the main contraceptive methods and percentage of women continuing the method at 1 year. Adapted from (Trussell 2007) [29]

\begin{tabular}{|c|c|c|c|}
\hline \multirow[t]{2}{*}{ Method } & \multicolumn{2}{|c|}{$\begin{array}{l}\% \text { of women experiencing } \\
\text { an unintended pregnancy } \\
\text { within the first year of use }\end{array}$} & \multirow[t]{2}{*}{$\begin{array}{l}\% \text { of women } \\
\text { continuing use at } \\
1 \text { year }\end{array}$} \\
\hline & Typical use & Perfect use & \\
\hline No method & 85 & 85 & - \\
\hline \multicolumn{4}{|c|}{ Non-pharmacological methods } \\
\hline Female condom & 21 & 5 & 41 \\
\hline Withdrawal & 20 & 4 & 46 \\
\hline Diaphragm & 17 & 16 & 57 \\
\hline Ovulation method & 23 & 3 & \\
\hline Male condom & 13 & 2 & 43 \\
\hline Copper IUD & 0.8 & 0.6 & 78 \\
\hline \multicolumn{4}{|c|}{ Pharmacological methods } \\
\hline COCs and POPs & 7 & 0.3 & 67 \\
\hline Patch & 7 & 0.3 & 67 \\
\hline Vaginal ring & 7 & 0.3 & 67 \\
\hline Injectable & 4 & 0.2 & 56 \\
\hline LNG-IUD & $0.1-0.2$ & $0.1-0.2$ & 80 \\
\hline Implant & 0.1 & 0.1 & 89 \\
\hline \multicolumn{4}{|l|}{ Surgical methods } \\
\hline Tubal occlusion & 0.5 & 0.5 & 100 \\
\hline Vasectomy & 0.15 & 0.1 & 100 \\
\hline
\end{tabular}

$I U D$ intrauterine device, $C O C$ combined oral contraceptive, $P O P$ progestin-only pill, $L N G$-IUD levonorgestrel intrauterine device

Table 3 Percentage of couples in fertile age that chose a specific contraceptive method in 2018. Adapted from the Population Reference Bureau, 2019 [30]

\begin{tabular}{lclll}
\hline Method & World & Europe & Italy & $\begin{array}{l}\text { Devel- } \\
\text { oping } \\
\text { countries }\end{array}$ \\
\hline All methods & 62 & 70 & 65.1 & 54 \\
$\begin{array}{l}\text { Non-pharmacological methods } \\
\text { IUD }\end{array}$ & 13 & 11 & 4.8 & 13 \\
Condom & 8 & 21 & 20.9 & 6 \\
$\quad \begin{array}{l}\text { Withdrawal } \\
\text { Pharmacological methods }\end{array}$ & 4 & 2 & 17.5 & 3 \\
$\quad \begin{array}{l}\text { Oral contraceptives } \\
\text { Surgical methods }\end{array}$ & 9 & 20 & 20.3 & 8 \\
$\quad$ Male sterilization & - & - & - & - \\
Female sterilization & 18 & 22 & 5.8 & 20 \\
\hline
\end{tabular}

$I U D$ intrauterine device

Italy CICs are not available and implants are rarely used. Male sterilization is rare, as in the rest of the world; male condom use and withdrawal are widely used, with consequences linked to poor efficacy (Table 3) [30]. 


\section{Design of the best practice position statement}

The present best statement has been designed, in collaboration with obstetric teams with experience in the management of kidney patients, to support clinical nephrologists with practical indications on the most commonly used birth control methods and treatments, with the final aim of giving nephrologists the tools they need to actively participate in the choice of a contraceptive agent, in keeping with obstetric indications and patient preferences.

It is organized according to type and efficacy of contraceptive agents, trying to identify, for each of them, the limits and the specific indications or contraindications in different categories of CKD patients. The evidence related to CKD is low, and the indications and suggestions given are based on similar diseases (immunologic diseases), on CKD complications (hypertension) or on the presence of related diseases, such as diabetes. Within these limits, we have tried to summarize a counselling policy suitable for women in different phases of CKD, dialysis and transplantation.

\section{Combined hormonal contraceptives (aestro-progestinic agents agents)}

- Combined hormonal contraceptives (CHCs) are widely used and highly effective, but the cardiovascular and thrombotic risks are high and this can be of particular relevance for CKD patients (grade of evidence: high for the general population, low for the specific categories related to CKD patients).

- There is no absolute contraindication for $\mathrm{CHC}$ use in CKD patients without hypertension or immunologic diseases or those taking immunosuppressive drugs (grade of evidence: low for the specific categories related to CKD patients).

- No correlation between CHC and neoplastic risk has been established. An increase in incidence of breast and cervical cancer is debated; likewise, the protective effect on ovarian, endometrial and colorectal cancer is controversial (grade of evidence: debated in relation to the general population, no studies on CKD patients).

- CHC can induce or worsen albuminuria; this side effect is usually reversible at discontinuation in patients without CKD. The pathogenesis is not known but seems to be independent from blood pressure (grade of evidence: high for the general population, no studies on CKD patients)

- The use of a patch is associated with higher circulating hormonal levels, with consequently higher risk of adverse effects (grade of evidence: high for the general population, low for the specific categories related to CKD patients).

- Vaginitis and leucorrhoea are more frequent with a vaginal ring and a ring may favour urinary tract infections (grade of evidence: high for the general population, low for the specific categories related to CKD patients).

- Alternatives should be systematically sought in advanced and progressive CKD, immunologic diseases, and complicated kidney transplantation; the presence of proteinuria and hypertension increases the risk of adverse effects (grade of evidence: low for the specific categories related to CKD patients, but supported by shared clinical views).

Combined hormonal contraceptives are contraceptives that contain different types of oestrogen and progestin, combined in different dosages. They are the first, and still the most widely used contraceptives, colloquially referred to as "the pill". They are highly effective (Pearl Index $<1$ with perfect use, see Table 2). Combined hormonal contraceptives exist in four forms: oral contraceptives (COCs), transdermal patch $(\mathrm{P})$, transvaginal ring $(\mathrm{CVR})$ and combined injectable contraceptives (CICs).

Besides being used for birth control, combined hormonal oral contraceptives are routinely prescribed to non-CKD patients for dysmenorrhea (painful menstruation), functional ovarian cysts, hypermenorrhea (abundant menstruation), polymenorrhea (frequent menstruation), endometriosis or acne.

The Medical Eligibility Criteria take very few nephropathies into account: diabetic nephropathy in category 3 or 4 (depending on severity), while diabetes without vascular disease is included in category 2 ; when normotensive, well controlled and in remission, SLE is also included in category 2 but the presence of antiphospholipid antibodies warrants its inclusion in category 4 (absolute contraindication). Kidney transplantation is categorized in more than one way (category 2 if "non- complicated", up to 4 in the presence of organ failure or acute/chronic rejection). Hypertension, which often coexists in kidney disease, is in category 3, even when moderate and controlled by therapy. [28]

Combined oral contraceptives (COCs) or "the pill", are one of the most effective contraceptive methods (failure rate with perfect use: $0.3 \%$, Table 2 ) and are widely used throughout the world. Birth control pills contain different types of two hormonal components, progestin and oestrogen, combined in different dosages. COCs inhibit the release of $\mathrm{GnRH}$, thus blocking the release of the hypophysis hormones that stimulate ovulation, alter the endometrium and cause thickening of the cervical mucus. Birth control pills must be taken for between 21 and 24 days per month, with 4-7 days of pause between cycles, in which a suspension bleeding appears. Some COCs have the same dosage 
during the entire month (monophasic pills), others have different dosages (multiphasic pills), in order to better mimic natural hormonal fluctuations. The oestrogen typically associated with progestin is Ethinyl Estradiol (EE), with a dosage that varies from 10 to $35 \mathrm{mcg} /$ day ("low-dosage oestrogens" $<35 \mathrm{mcg} /$ day). New oestrogen-derivatives have recently been introduced (Estrogen Valerate, Estradiol) to minimize the oestrogen-related adverse effects of taking birth control pills, since they induce less liver protein synthesis (e.g. sex-hormone binding globulin, angiotensinogen and coagulation factors) (Table 4).

The first generation of contraceptive pills, developed in the 1960s, used a high concentration of oestrogen with progestin with androgenic activity; the second generation of hormonal contraceptives combined lower levels of oestrogens with various testosterone-derived progestins characterized by low but significant androgenic activity; the most widely used progestin in this category is Levonorgestrel (LNG). COCs in combination with Levonorgestrel have the lowest thromboembolic risk (Tables 5, 6) [31], but their androgenic effects must be considered before prescribing them to women with acne or hirsutism. Since the 1990s, further combined hormonal contraceptives have been developed, with different progestins; these are sometimes referred to as third-generation (those containing Desogestrel, Gestodene or Norgestimate) and fourth-generation contraceptives (those containing Norelgestromine, Etonogestrel,

Table 4 Main non-thromboembolic side effects of CHCs

\begin{tabular}{ll}
\hline Target & Complication \\
\hline Gastrointestinal & Nausea \\
Dermatological & Acne \\
Neurobehavioural & Decreased libido \\
& Depressed mood \\
& Headache \\
& Increased appetite \\
Gynecological & Breast tenderness \\
& Breakthrough bleeding \\
& Increased vaginal discharge \\
\hline
\end{tabular}

Table 6 Odds ratios comparing the risk of non-fatal venous thromboembolism in users of different contraceptives. Adapted from MEGA study [33]

\begin{tabular}{lll}
\hline Type of progestin & OR & $95 \%$ CI \\
\hline Levonorgestrel & 3.6 & $2.9-4.6$ \\
Gestodene & 5.6 & $3.7-8.4$ \\
Norgestimate & 5.9 & $1.7-21.0$ \\
Drospirenone & 6.3 & $2.9-13.7$ \\
Ciproterone acetate & 6.8 & $4.7-10.0$ \\
Desogestrel & 7.3 & $5.3-10.0$ \\
\hline
\end{tabular}

$O R$ odds ratio, $C I$ confidence interval

Drospirenone or Dienogest). The classification in different "generations", however, is not standardized, and may differ between publications, thus making it advisable to refer to the specific contents and not merely to a "generation".

The transdermal CHC or combined patch $(\mathrm{P})$ is a 4.6$\mathrm{cm}^{2}$ patch that must be replaced every week, for three consecutive weeks, followed by a patch-free week. The active principles contained in a single patch are Ethinyl Estradiol $(6 \mathrm{mg})$ and Norelgestromin $(600 \mathrm{mcg})$, releasing on average $34 \mathrm{mcg} /$ day of Ethinyl Estradiol and $203 \mathrm{mcg} /$ day of Norelgestromin. Efficacy and cycle control are similar to those of COCs, but the patch has the advantage of avoiding first-pass effect in the liver. The circulating levels of oestrogen are usually higher in transdermal than in oral CHCs.

The combined vaginal ring (CVR), manufactured from ethylene-co-vinyl acetate, is a flexible atoxic ring measuring $5.4 \mathrm{~cm}$ in diameter that contains Etonogestrel $(11.7 \mathrm{mg})$ and Ethinyl Estradiol $(2.7 \mathrm{mg}$ ), releasing on average $120 \mathrm{mcg} /$ day of Etonogestrel and $15 \mathrm{mcg} /$ day of Ethinyl Estradiol. The ring is kept in the vagina for 3 consecutive weeks, and is replaced after 1 ring-free week. Efficacy and control of the cycle are optimal, and the principles are not subject to first pass effect in the liver. Moreover, the oestrogen dose is very low.

The recently developed injectable CHCs (combined injectable contraceptives) contain either $25 \mathrm{mg}$ of Depotmedroxyprogesterone acetate and $5 \mathrm{mg}$ of Estradiol Cipion
Table 5 Risk of developing deep venous thrombosis in per year of use. Modified from the European Medicines Agency, 2014 [31]

\begin{tabular}{ll}
\hline $\begin{array}{l}\text { Hormonal contraceptive use } \\
\text { Combined hormonal contraceptives (CHCs) }\end{array}$ & $\begin{array}{l}\text { Cases of deep } \\
\text { venous thrombosis }\end{array}$ \\
\hline No CHC (and not pregnant) & $2 / 10,000$ women \\
CHC containing Levonorgestrel, Norethisterone or Norgestimate & $5-7 / 10,000$ women \\
CHC containing Etonogestrel or Norelgestromin & $6-12 / 10,000$ women \\
CHC containing Drospirenone, Gestodene or Desogestrel & $9-12 / 10,000$ women \\
CHC containing Chlormadinone, Dienogest or Nomegestrol & Not yet known ${ }^{\text {a }}$ \\
\hline
\end{tabular}

CHC combined hormonal contraceptive

${ }^{\mathrm{a}}$ Further studies are ongoing or planned to collect more data 
or $50 \mathrm{mg}$ of Norethisterone Enanthate and $5 \mathrm{mg}$ of Estradiol Valerate. Combined injectable contraceptives have good pharmacokinetics and are less subject to individual variations, but can cause spotting and bleeding. Combined injectable contraceptives are currently not available in Italy and are mostly used in developing countries, because the therapy is easy to manage (one injection per month) and inexpensive.

\section{Risks and side effects of CHCs}

In spite of their high efficacy, CHCs are not devoid of side effects. Table 4 reports their main non-thromboembolic side effects.

Thromboembolic and cardiovascular events are rare, although potentially severe; the risk of venous thromboembolism varies between CHCs, depending on the amount of oestrogen and type of progestin they contain, ranging from 5 to 12 cases per 10,000 women, a two- to five-fold increase with respect to the usual incidence of 2 per 10,000 in women not using CHCs (Tables 5, 6) [31]. Overall, the risk is higher in the first year of use and is correlated with oestrogen dose. A meta-analysis published in 2018 analysed the risk of venous thrombosis associated with different types of combined oral contraceptives: the risk was lowest on COCs containing Levonorgestrel, followed by Gestodene and Cyproterone and highest on those containing Desogestrel (according to Oedingen, RR 1.46; 95\% CI 1.33-1.59 [32]). However, many studies lack information on potential confounders such as family history, body mass index, smoking and, most importantly, duration of use [32-36].

The association between the use of oral contraceptives and hypertension has been known since 1967, but the pathogenesis is still not fully clear. Genetic predisposition, duration of treatment, age and obesity are probably contributing factors. Oestrogens stimulate the hepatic synthesis of angiotensinogen, and activate the renin-aldosterone system; renal and peripheral hemodynamic alterations have been reported. Progestins can also increase blood pressure, albeit less significantly, probably via increased sodium retention; the effect seems to be of shorter duration, leading to the conclusion that progestin-only agents are less dangerous from this point of view [37-40].

A large body of evidence supports an increased risk of developing or worsening of albuminuria (OR 1.90; CI 1.23-2.93, according to Monster 2001 [43]). The increase is usually modest and reversible after discontinuation of $\mathrm{CHCs}$, but must be taken into consideration when a $\mathrm{CHC}$ is prescribed to a CKD patient. The increase in urinary albumin excretion is modulated by age (increasing in older women) and type of oestrogen; it tends to be higher on second- or third-generation CHCs. The pathogenesis is not fully known, but may be related to a haemodynamic effect. This side effect underlines the fact that $\mathrm{CHCs}$ ' long-term effects on kidney function are not fully understood. Although there is currently no evidence of a CHC-related predisposition to renal disease, some authors suggest that $\mathrm{CHCs}$ may represent a "first hit" in the development of CKD. In case of prescription of CHCs to patients with a kidney ailment, it is advisable to carry out periodic controls of proteinuria [40-45].

Drospirenone and the other fourth-generation progestins sometimes increase potassium levels because of their antimineralocorticoid effects, and should be used with care in patients with electrolyte disturbances [46].

The evidence of CHCs posing a cancer risk is controversial, as studies are highly heterogeneous in terms of population characteristics, type of the contraceptive, and duration of assumption. Furthermore, the long-term studies we have regard mainly first-generation, high-dosage pills, and the long-term effects of the more recent formulations are not yet known.

Several epidemiological studies and a systematic review published in 2003 reported an association between HPVrelated cervical cancer and use of COCs; the data was not confirmed in a recent meta-analysis, suggesting that this association is related to the fact that condoms are seldom used in patients on CHCs, with a consequent higher incidence of HPV infections [47-56].

An increase in breast cancer is controversial; some data suggest a slight but significant increase in women using COCs (Gierisch 2013: OR 1.08; 95\% CI 1.00-1.17 [56]), most frequently in triple-negative forms. The incidence of breast cancer decreases 5-10 years after a woman stops taking birth control pills [49, 56-69].

Conversely, the incidence of some cancers is significantly reduced by oral contraceptive use, regardless of the duration of therapy. This holds true for colorectal cancer (see Gierisch 2013: OR 0.86; CI 0.79-0.95 [56]) and endometrial cancer (see Gierisch 2013: OR 0.57; CI 0.43-0.77 [56]). CHCs are also associated with benign hepatic tumours, including hepatic adenomas or focal nodular hyperplasia, which rarely turn into a malignant hepato-cellular carcinoma. Furthermore, COC users, whether they are without predisposing factors or are carriers of BRCA1/BRCA2, apparently have a reduced risk of ovarian epithelial cancer [49, 56, 57, 70-79].

In summary, CHCs seem to protect against some types of cancers and to increase the risk of developing others. Since quantifying this risk is extremely difficult, the risk balance could be considered neutral and the decision on whether or not to prescribe this type of contraceptive should be based on other considerations. The only exception, according to $\mathrm{WHO}$, is the presence or history of breast cancer.

The side effects of taking $\mathrm{CHCs}$ could be expected to be similar in their transdermal, vaginal and oral formulations; however, a Cochrane review published in 2013 [80] showed that patch users have a higher rate 
of discontinuation than oral contraceptive users, due to adverse effects including breast discomfort, dysmenorrhea, nausea and vomiting, and local irritation. Ring users also reported less nausea, acne, irritability, depression, and emotional problems than COC users. The main complaints recorded with the transvaginal ring include vaginitis (OR 2.48; CI 1.39-4.43 with respect to oral agents [80]) and leucorrhoea (OR 3.21; CI 1.61-6.40 [80]), but less vaginal dryness. These effects may be of particular relevance in immunosuppressed patients or in patients with frequent urinary tract infections [80].

A potential favourable aspect is the fact that transdermal and vaginal preparations do not undergo first pass liver metabolism; therefore, they have a lower risk of potentially dangerous pharmacologic interferences involving the cytochrome P4503A4. This is particularly important in the case of calcineurin inhibitors, metabolized by the same pathway. In fact $\mathrm{CHCs}$ and progestin-only contraceptives have an inhibitory effect on P4503A4, thus increasing the concentration of calcineurin inhibitors, in particular Cyclosporine. Conversely, calcineurin inhibitors (in particular Tacrolimus) have an inductive effect on P4503A4, potentially reducing contraceptive efficacy [81-83].

Progestin-only contraceptives (POPs, injectables, implants)

Progestin-only contraceptives represent an effective alternative to $\mathrm{CHCs}$, mainly due to a better cardiovascular profile (grade of evidence: high for the general population, low for the specific categories related to CKD patients).

There is no absolute contraindication for progestin-only contraceptive use in CKD patients (grade of evidence: high for the general population, low for the specific categories related to CKD patients).

Weight gain is a potential side effect (grade of evidence: high for the general population, low for the specific categories related to CKD patients).
Potential interference with liver metabolism should be considered in cases of calcineurin inhibitors (grade of evidence: high for the general population, low for the specific categories related to CKD patients).

Progestin-only contraceptives act through inhibition of the release of GnRH, by modifying the composition of the cervical mucus making it impenetrable, and by reducing endometrial thickness, impairing implantation, and affecting tubal motility. The main advantage of progestin-only contraceptives lies in their minimal (or absent) impact on coagulation and blood pressure, thus making them good alternatives in women in a WHO MEC category 3 or 4 for combined hormonal contraceptives, which is the case for many women with CKD. Furthermore, these agents can be used postpartum and during lactation. However, although usually mild, weight gain can be an important drawback, in particular for obese and overweight patients [29, 84-88].

The contraindications and warnings identified by WHO are generally mild: category 1-2 hypertension; SLE 2, and SLE 3, in the presence of anti-phospholipid antibodies (Tables 7, 8). Kidney transplantation is rated 2, independently from the presence of hypertension, proteinuria or functional reduction. Diabetes-related nephropathy is rated 2 regarding progestin-only pills or implants, and rated 3 with respect to injectable progestins [31]. Several different approaches are available: POPs (progestin-only pillx or "minipillx"); and the depot method, either via intramuscular administration or a subdermal implant.

POP therapy available in Italy consists of Desogestrel $(75 \mathrm{mcg} / \mathrm{day})$ that must be taken every day, without interruptions; elsewhere in Europe and in other settings, the most widely used minipills contain Desogestrel (as in Italy) or Norethisterone $(350 \mathrm{mcg} /$ day $)$; Norethisterone is the only POP available in the United States. The failure rate with perfect use is similar to COCs', but the absence of oestrogens reduces control of the cycle, potentially causing spotting
Table 7 WHO indications regarding hypertension and diseases of nephrological interest

\begin{tabular}{llll}
\hline Disease & $\begin{array}{l}\text { POPs, implants, } \\
\text { injectable }\end{array}$ & Cu-IUD & LNG-IUD \\
\hline Adequately controlled hypertension & $1^{\mathrm{a}}$ & 1 & 1 \\
Diabetic nephropaty & $2^{\mathrm{b}}$ & 1 & 2 \\
SLE & 2 & 1 & 2 \\
SLE+ positive antiphospholipid antibodies & 3 & 1 & 3 \\
Uncomplicated kidney transplantation & 2 & 2 & 2 \\
Complicated kidney transplantation & 2 & 2 (continuation)/3 & 2 (continua- \\
& & (initiation) & tion)/3 (ini- \\
& & & tiation) \\
\hline
\end{tabular}

WHO World Health Organization, SLE systemic lupus erytematosus, $C H C$ combined hormonal contraceptive, $P O P$ progestin-only pill, $C u$-IUD copper-bearing intrauterine device, $L N G$-IUD levonorgestrel intrauterine device

${ }^{\mathrm{a} C}$ Cat. 2 implant

${ }^{\mathrm{b}}$ Cat. 3 injectable 
Table 8 Indications on contraception for SLE patients. Adapted from references [28, 95, 106]

\begin{tabular}{llll}
\hline & CHCs & POPs & LNG-IUD \\
\hline SLE & & & 2 \\
WHO & 2 & 2 & Not available \\
EULAR & Can be considered & No risk flare & Can be offered to all patients \\
SAMMARITANO & No increased flare in stable patients & 3 & 3 \\
SLE + aPL & 4 & $\begin{array}{c}\text { Carefully weighed against the risk } \\
\text { of thrombosis (2B) }\end{array}$ & Can be offered to all patients \\
EUHO & controindicated & No risk thrombosis & No risk thrombosis \\
SAMMARITANO & Increased risk thrombosis. AVOID & &
\end{tabular}

CHC combined hormonal contraceptive, $P O P$ progestin-only pill, $L N G$-IUD levonorgestrel-intrauterine device, SLE systemic lupus erythematosus, $a P L$ antiphospholipid antibodies, WHO World Health Organization, EULAR the European League Against Rheumatism

or irregular menses; moreover, ingestion must be regular to reduce the risk of unintended pregnancies (Pearl Index, referred to typical use, is $1-5$, see Table 2).

POPs undergo first pass liver metabolism, potentially interacting with calcineurin inhibitors [82, 83].

Thanks to their safer cardiovascular profile, POPs are not contraindicated in dialysis patients; however, spotting may be bothersome in the case of heparin administration in dialysis. Conversely, since they reduce menstrual bleeding (or interrupt menses), they can be useful in patients with intense bleeding.

The thrombotic risk in patients taking a progestin-only contraceptive is debated. A Mexican trial [89] compared adverse effects in three group of 54 patients each, one group using COCs, one POPs, and one IUDs: four patients with systemic lupus erythematosus had thromboses while receiving hormones (two patients with COCs, two patients with POPs). On this basis, the contraceptive guidelines suggest caution in POP use in patients with systemic lupus erythematosus or nephrological complications: WHO puts progestin-only contraceptives in category 2 or 3 . In recent years, the evidence has been reassuring, suggesting a low thrombosis risk, and this contraceptive is being more widely used. The RCOG guidelines now state that "The available evidence does not demonstrate an increased risk associated with POPs" [89-93].

A meta-analysis showed that the risk of thromboembolism in women using a low-dosage progestin-only contraceptive is comparable to that of non-users (RR 1.03, CI 95\% 0.76-1.39 according to Mantha 2012 [94]) and does not increase even in women at high thromboembolic risk. Evidence on women with rheumatic diseases is lacking, and positions are different: WHO does not recommend use by patients with antiphospholipid antibodies (category 3 ), while RCOG considers progestin-only contraceptives a safe alternative to $\mathrm{CHCs}$ for patients with SLE, active nephritis and vascular diseases [90, 94].
In a recent review on contraception in patients with rheumatic diseases, Sammaritano concludes that progestin-only contraceptives are generally safe and that "the risks associated with any hormonal contraceptive method must be balanced with the risks of unintended pregnancy" [95].

Progestin-only subdermal implants (Etonogestrel or Levonorgestrel) are a fairly long-term (3 years), reversible and relatively safe method, with a failure rate of $0.1 \%$ (see Table 2). Their main adverse side effect is irregular menstrual bleeding or amenorrhea, as with POPs. WHO cautions against their use by patients with cardiovascular diseases or diabetes, mainly because of the risk of weight gain (although this is debated and weight gain is usually small). Implants can cause a reduction in bone mineral density, albeit less than those caused by other long-acting formulations (DMPA) [85, 96-102].

There are other injectable progestin-only therapies widely used as contraceptives. Two molecules are available: Depot-medroxy-progesterone acetate (DMPA) and Norethisterone Enanthate (NET-EN). Both highly effective, they differ in frequency of administration. Women taking DMPA are more likely to develop amenorrhoea, but there are no differences regarding other side effects. The injection of DMPA (150 mg) is used mostly in developing countries, because the injection is expensive (less than 1 dollar) and its effect lasts for 3 months. DMPA is available in Italy, but is only registered for use in treating endometrial and breast cancers. DMPA can reduce bone mineral density and this side effect can be relevant in patients on long-term steroid treatment, but the reduction tends to be reversible on discontinuation. Norethisterone Enanthate (NET-EN, dosage $200 \mathrm{mg}$ ), the other available injectable progestin-only contraceptive, has a duration of action of 2 months [103]. 


\section{Intrauterine devices (IUD)}

- Medicated or non-medicated intrauterine devices are efficacious contraceptive alternatives in CKD patients (grade of evidence: high for the general population, low for the specific categories related to CKD patients).

- Intrauterine devices are associated with a slightly higher risk of pelvic infections in the first 20 days after placement, and their use is restricted in patients with malformations or pyelonephritis, and in those on peritoneal dialysis. Attention must be paid to the placement procedure (grade of evidence: high for the general population, low for the specific categories related to CKD patients).

- The main advantage of the non-medicated copper-only IUD is the avoidance of drug interactions; LNG-IUD has the advantage of reducing the amount of menstrual blood loss (grade of evidence: high for the general population, low for the specific categories related to CKD patients).

- Extrauterine pregnancies appear to be more frequent in women using IUDs (grade of evidence: high for the general population, low for the specific categories related to CKD patients).

IUDs (intrauterine devices, also called "coils") are small, T-shaped, flexible devices that are inserted in the uterus; they stay in place for 3, 5 or 10 years, depending on the total surface occupied by the copper and on the dosage of the progestin released, but can easily be removed before term if complications arise or a woman wishes to conceive.

Two main types of IUDs are available: the copper-only IUD (5-10 years of efficacy, according to type), that do not contain any active drugs, and a medicated form, containing long-acting progesterone (Levonorgestrel, LNG-IUD, which has 3-5 years of efficacy).

The copper-only IUDs release copper ions, which are toxic to sperm; moreover, they induce local modifications of the endometrium and cervical mucus that prevent fertilization. The medicated forms release a small dose of Levonorgestrel (14-20 mcg/day) that thickens the cervical mucus, preventing the movement of spermatozoa. To a lesser degree, they can also impair ovulation. Their placement in primiparas and multiparas is easy because the cervix is already dilated, while in nulliparas it can be more complicated, in particular for the older forms; recent data show that the placement may be easy also in nulliparous women with a minimal discomfort [103]. Placement in patients with previous caesarean section requires caution (for example, ultrasound-guided placement). Placement can sometimes be painful, but the procedure is fast [104]. A copper-bearing IUD can also be inserted as an emergency contraceptive method within $120 \mathrm{~h}$ from unprotected sexual intercourse [105].

The IUD is a very effective method, with a low risk of failure $(0.1-0.6 \%$, Table 3$)$. Since it is a long-term contraceptive method, compliance is very high. Its greatest advantage is probably that it makes it possible to avoid using active drugs, a safer choice in diseases associated with thromboembolic risk, risk of hypertension and weight gain.

According to WHO indications, the copper-bearing IUD can be safely used in patients with hypertension, diabetes with nephropathy, deep thromboembolism, and lupus. Antiphospholipid antibodies are instead a contraindication for the use of a medicated IUD [29].

The thrombotic risk of LNG-IUDs, given their progestin content, has been debated, but the evidence shows that the risk is low. A meta-analysis by Mantha et al. showed that the LNG-IUD was not associated with a higher thrombotic risk (RR 0.61, CI 95\% 0.24-1.53) [94]. Sammaritano concluded that LNG-IUDs are safe and effective even in patients with rheumatic diseases [95]. According to EULAR (the European League Against Rheumatism), LNG-containing IUDs should be considered only if the benefits of the released hormone outweigh the risk of thrombosis". RCOG states that there is little or no increased risk of VTE associated with the use of an LNG-IUD [94, 95, 106, 107].

IUDs are associated with a higher risk of extrauterine pregnancy, an event that, however, has a very low cumulative incidence and seems to have been associated with the first generation of IUDs. The risk is about 6 times higher than in the overall pregnant population and also exists in cases of previous use (OR 1.7\% CI 95\% 1.39-2.13, according to $\mathrm{Li}[108]$ ) and above all in cases of IUD failure (OR $16.43 \%, 95 \%$ CI 10.42-25.89, according to Li [108]; 3.99 (95\% CI 2.06-7.72 according to Gaskins [109]). Two rare adverse effects are perforation of the uterus, related to the insertion procedure, and expulsion of the device. Commonly, the copper-bearing IUD induces a small increase in duration of menstruation and blood loss, while the LNG-IUD often reduces the flow and sometimes induces amenorrhea, and may therefore be useful in patients with anaemia [108-114].

The risk of infection related to IUDs is a matter of ongoing debate. The timing of the increased risk is interesting: in a large retrospective study, cited in the RCOG guidelines, the overall risk of PID was $0.54 \%$ (95\% CI 0.48-0.60) within 90 days after placement; according to a review of 13 trials, the risk of contracting a pelvic inflammatory disease is generally higher in the 20 days following IUD placement, suggesting that most infections are associated with the placement procedure. This means that many could therefore be avoided by a combination of pre-placement identification of infections (bacteriologic testing), providing treatment if infections are found, and careful asepsis and/or antibiotic prophylaxis. After this time, the risk remains low unless 
there is exposure to sexually-transmitted infections. It is not clear if the risk of infection is lower with LNG-IUDs than $\mathrm{Cu}$-IUDs: one trial reported that the cumulative rate of PID was lower in women using LNG-IUDs compared to women using $\mathrm{Cu}$-IUDs (cumulative discontinuation rates caused by PID for $\mathrm{Cu}$-IUD 2.0 versus LNG-IUD 0.5, $\mathrm{p}<0.013$ ). However, in another study, PID rates did not differ between the two methods (termination rate because of PID: 0.7 for both Cu-IUDs and LNG-IUDs) [106, 115-118].

Regarding kidney transplantation, intrauterine devices are rated in category 3 for initiation of contraception, 2 for continuation [28]. Their placement in category 3 is probably related to occasional failure reports, but there is no evidence of an increase in risk of infections. IUDs are historically contraindicated in immunosuppressed women, since the IUD elicits a local inflammation that could be inhibited by immunosuppressive therapy. However, recent data do not confirm this finding, as they suggest that local inflammation induced by IUD involves macrophages, whereas iatrogenic immunosuppression involves lymphocytes; the few studies addressed to this question failed to find a significant difference in IUD failure between patients on immunosuppressive drugs and healthy women. There are no data regarding the risk of infection in transplanted patients, but no increase in the rate of infection has been found in immunocompromised HIV positive women using IUDs. It is against this background that the US Center for Disease Control and Prevention's Medical Eligibility Criteria (CDC-MEC) for 2016 supports the use of the IUD only following uncomplicated kidney transplantation. The CDC MEC warns that the risks may outweigh the benefits for complicated transplants [28, $119,120]$.

\section{Barrier methods}

- Barrier methods include condoms, diaphragms, cervical caps and sponges. Their main drawback is their low efficacy, often linked to errors in use (grade of evidence: high for the general population, low for the specific categories related to CKD patients).

- The barrier methods that contemplate the use of a spermicide, such as diaphragms or cervical caps, can increase the risk of urinary tract infections and should be used with care in immunosuppressed patients and in patients with urinary tract infections and/or malformations (grade of evidence: high for the general population, low for the specific category related to CKD patients).

- The main advantage of using barrier methods is their lack of side effects (grade of evidence: high for the general population, low for the specific categories related to CKD patients).
- The condom (male or female) is the only contraceptive method that protects against sexually transmitted diseases (grade of evidence: high for the general population, low for the specific categories related to CKD patients).

Barrier methods are contraceptives that function by preventing direct contact between spermatozoa and an ovum. However, barrier methods are not as effective as other methods and cannot be considered an effective long-term contraceptive option, even if they are safe and do not interact with drugs. WHO does not pose any contraindications to their use [28].

The most widespread barrier method is the male condom, but other barrier methods exist: the diaphragm (plus spermicide), the cervical cap (plus spermicide), the cervical sponge (not available in Italy) and the female condom (Table 9). The failure rate depends largely on correct positioning of the device and on the method itself. Spermicide use increases the risk of urinary tract infections, in particular those caused by Staphylococcus saprophyticus and E. coli; the pathogenesis is not completely understood, but it seems that spermicides may alter the vaginal environment, leading to a greater colonization by uropathogens. Care must therefore be taken if they are used by immunosuppressed patients or by patients with frequent urinary tract infections or malformations [121-127].

\section{Emergency contraception}

- Emergency contraception is based on a high dosage of progestin or placement of a copper-bearing IUD. The use of emergency contraception should be considered within $120 \mathrm{~h}$ after unprotected sexual intercourse (grade of evidence: high for the general population, low for the specific categories related to CKD patients).

- The main drawbacks are the risk of nausea and vomiting and potential interaction with calcineurin inhibitors (grade of evidence: high for the general population, low for the specific categories related to CKD patients).

Emergency contraception is the term used for forms of contraception that are effective in preventing an unintended pregnancy when administered within a specified period of time after unprotected, or inefficaciously protected sexual intercourse. Emergency contraception can be achieved by administering orally a high dose of progestin or the selective progestin receptor modulator (in Italy the available formulations are a single dose of $30 \mathrm{mg}$ of Ulipristal acetate or a single dose of $1.5 \mathrm{mg}$ of Levonorgestrel) or by placing an IUD within 5 days after unprotected intercourse; due to their lower cost, copper-bearing IUDs are more often employed. Their efficacy decreases as time passes and is variable: 
Table 9 Failure rates, advantages and disadvantages of barrier methods. Adapted from [121]

\begin{tabular}{|c|c|c|c|c|}
\hline Method & Image & Advantages & Disadvantages & Failure rate* $(\%)$ \\
\hline Male condom & & $\begin{array}{l}\text { Little training needed; it is indicate for } \\
\text { unexpected or occasional sex acts or in } \\
\text { teenagers that are insecure about their } \\
\text { bodies; inexpensive }\end{array}$ & $\begin{array}{l}\text { Not reusable; it can reduce excitation and } \\
\text { cause discomfort }\end{array}$ & $2-15$ \\
\hline Female condom & & $\begin{array}{l}\text { Latex free; more suitable when used with } \\
\text { a lubricant }\end{array}$ & $\begin{array}{l}\text { More complicated insertion than male } \\
\text { condom; training is necessary }\end{array}$ & $5-21$ \\
\hline Diaphragm & & Reusable; inexpensive & $\begin{array}{l}\text { Does not protect against STDs; must be } \\
\text { inserted before intercourse; training is } \\
\text { necessary; discomfort during intercourse; } \\
\text { not always suitable for multiparas or } \\
\text { women with prolapse; not latex free; the } \\
\text { use of spermicides can irritate the vagina } \\
\text { and induce vaginal infections }\end{array}$ & $6-16$ \\
\hline Cervical Cap & & Same as the diaphragm & Same as the diaphragm & $6-16$ \\
\hline Sponge & & Same as the diaphragm & $\begin{array}{l}\text { Same as the diaphragm, but contains } \\
\text { spermicide }\end{array}$ & $9-16$ \\
\hline
\end{tabular}

STD sexually transmitted disease

the efficacy of progestin ranges from 54 to $99 \%$ within the first $72 \mathrm{~h}$; Ulipristal acetate is three times more effective than Levonorgestrel. The IUD has an efficacy of $99 \%$ when placed within $120 \mathrm{~h}$ after unprotected intercourse [128-132].

The mechanism of action of high-dose progestin consists in thickening the cervical mucus and interfering with ovulation: before the peak of LH (luteinizing hormone) they inhibit follicular maturation and prevent ovulation; UPA inhibits ovulation even after the onset of the LH peak, delaying ovulation for at least 5 days. The side effects of highdose progestin are not different from those reported for POPs and other progestin formulations, although vomiting is more frequent. In case of vomiting within $2 \mathrm{~h}$, the dose should be repeated, but the systematic use of anti-emetic drugs is not recommended. In spite of the high dosage of progesterone, this contraceptive does not contain oestrogens and can be considered reasonably safe in patients with kidney disease; however, it is not recommended in severe chronic liver disease. WHO does not warn against its use in any category, including the presence of deep venous thrombosis. Frequent use of EC in women with MEC category 2, 3 or 4 has to be discouraged; furthermore, a high dose of a steroid contraceptive can interact with the metabolisms of several drugs, including calcineurin inhibitors (see section on combined hormonal contraceptives). The oral emergency contraceptives do not prevent the implantation of a fertilized egg and do not affect an existing pregnancy. After taking an emergency contraceptive, patients often have menstrual irregularities [30, 128-132].

\section{Surgical sterilization}

- Surgical sterilization is the only non-reversible contraceptive method (grade of evidence: high for the general population, no data for the specific categories related to CKD patients).

- The main risks are those linked with the surgical procedure (grade of evidence: high for the general population, no data for the specific categories related to CKD patients).

Surgical sterilization is the only non-reversible contraceptive method; it includes female surgical sterilization (tubal sterilization) and male surgical sterilisation (vasectomy). While it is the method least frequently used in Europe, sterilization is the contraceptive method most used by women elsewhere in the world, particularly women in China, India and the United States. Before 1978, surgical sterilization was illegal in Italy (Article 552/1930 of the Italian Criminal 
Code); since 1978, (Law 194/78. Article 22), an adult woman has been allowed to ask for tubal sterilization if the procedure is expected to provide a health or psychological, benefit. In 2018 6\% of married women in Italy chose this method (Table 3) [30].

Female sterilization (salpingectomy) consists in the removal of the fallopian tubes or in their ligature (occlusion), and can be performed by laparoscopy or by laparotomy. The first procedure involves ligature of the tubes and removal of a small section; because of the possibility of spontaneous reopening of the tubes and failure of the procedure, even if correctly performed, and because of the evidence that ovarian cancer often originates in the fimbriae of the fallopian tubes, the surgical technique generally used nowadays consists in the removal of the tubes in their entirety, followed by histological analysis. Sometimes, generally during caesarean section, the removal of the tubes is technically difficult or not possible and in these cases occlusion is preferred.

WHO recommends caution in patients with kidney diseases. In fact, sterilization bears the risks of infection and haemorrhage, not specifically linked to the procedure itself, but common in all types of abdominal surgery [28].

\section{Abortion}

- Abortion should not be considered a birth control procedure, and should not be used as such (grade of evidence: high for the general population, no data for the specific categories related to CKD patients).

- Surgical abortion may impair subsequent fertility and involves the risks common to all surgical procedures (grade of evidence: high for the general population, no data for the specific categories related to CKD patients).

- There is limited evidence regarding the use of "medical", drug-induced abortion in CKD patients, and although it is less invasive, the procedure cannot be considered to be safe for CKD patients (grade of evidence: no data for the specific categories related to CKD patients).

Abortion is defined as the spontaneous or provoked interruption of a pregnancy before the 180th day (23rd week) of gestation. According to this definition, abortion cannot be considered a contraceptive method, since conception has already occurred. We have included it in this review because it is an important item in reproductive health. Elective abortion can be voluntary, when requested by a pregnant woman, or therapeutic, when indicated for clinical or psychological reasons. Abortion is a controversial question throughout the world and laws regulating voluntary termination of pregnancy vary between countries. In some developing countries abortion is illegal but unofficially practiced, with high risks for women's health and lives. In Europe, abortion is illegal in Malta, San Marino and Vatican City. In Italy a 1978 law (194/1978) legalized voluntary abortion and since then abortion without medical indication has been legal in the first 90 days of pregnancy, while abortion for therapeutic reasons can be practiced after the 90th day if the pregnancy represents a serious hazard for the woman's life or well-being [133-135].

The procedure can be medical or surgical.

The drugs used for medical termination of pregnancy are Mifepristone and Misoprostol. Limited data are available on the use of these drugs in patients with CKD. Mifepristone is metabolized by the liver, leading to potential drug interactions, while Misoprostol is excreted by the kidneys. In patients with reduced clearance, this can lead to increased bioavailability and higher peak concentrations of Misoprostol. There is not yet enough data available to show that reducing doses is advisable, and clinical surveillance is needed in patients with severe CKD. Animal studies have shown a worsening in kidney function after Mifepristone, but data on CKD women are not available. We were able to find only one published case series of three women with CKD (stage 4 or 5) which reported no complications after taking medical abortifacients [136, 137]. Medication may be preferable to a surgical procedure (vacuum aspiration and/or curettage) for women who wish to become pregnant again, because interventions on the uterus can impair subsequent placentation, especially if repeated. A Cochrane meta-analysis has shown that a medical procedure in the first trimester of pregnancy is related to a longer duration of bleeding than a surgical procedure (OR 2.94, 95\% CI 2.10-3.78), but the difference in total blood loss is not significant (OR 1.90, 95\% CI 0.05-3.75); this could be relevant in patients with anaemia $[137,138]$. Surgical procedures are considered to low complexity ones, but once more data regarding the preferred procedure in patients with CKD are not available.

\section{Summary remarks}

Pregnancy is a challenge in CKD, but its improved probability of success makes contraception another important challenge for CKD patients.

In the early CKD stages (stages 1-2-3a), in patients without hypertension or proteinuria (except in SLE + aPL), virtually all options are available. Particular care should be paid to an increase in or development of proteinuria in predisposed patients and to the development of urinary tract infections, in particular when patients use spermicide or a vaginal ring.

The contraceptive pill should be avoided in every CKD stage in hypertensive patients and in patients in stages $3 \mathrm{~b}-5$, as well as in patients with pro-coagulatory status, including systemic diseases such as SLE, or nephrotic proteinuria. The 


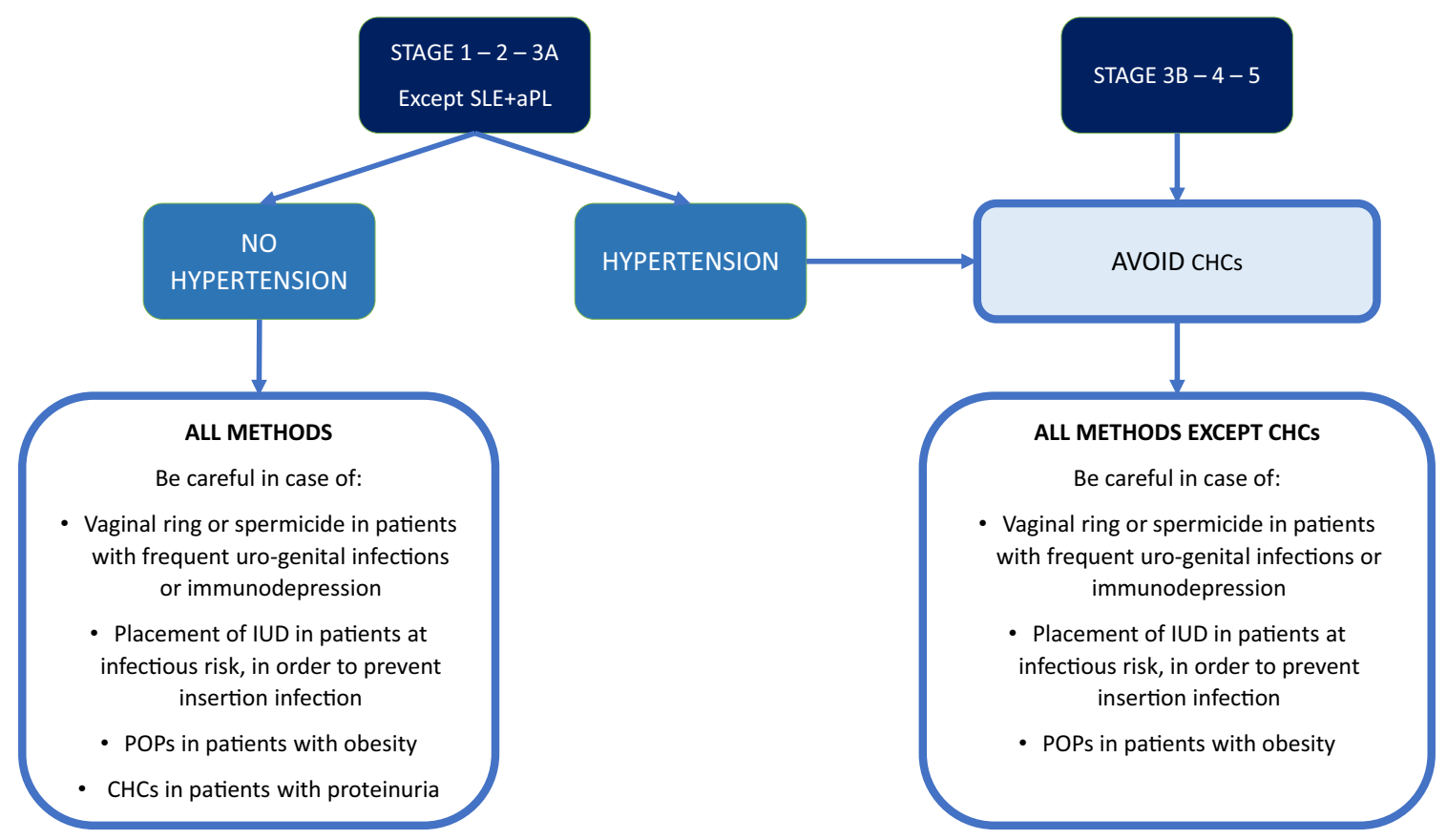

Fig. 1 Flow chart on contraception in CKD patients. SLE systemic lupus erythematosus, $a P L$ antiphospholipid antibodies, IUD intrauterine device, $P O P$ progestin-only pill, $C H C$ combined hormonal contraceptive, $C K D$ chronic kidney disease

options in these cases include progestin-only contraceptives, which can, however, cause spotting (sometimes increased by heparin use in dialysis patients), intrauterine devices, barrier methods and surgical sterilization.

As previously mentioned, the use of spermicides and the vaginal ring should be prescribed and monitored with care in patients with recurrent urinary tract infections, while data on intrauterine devices suggest that the risk of pelvic infection is slightly higher after insertion; infection can be avoided by previous targeted treatment, ensuring aseptic insertion, and possible antibiotic prophylaxis.

Dialysis patients are not good candidates for the pill, and alternative solutions should be sought; given their reduced fertility, barrier methods or non-medicated intrauterine devices are possible alternatives, while no contraindications, besides spotting, exist for progestin-only contraceptive agents.

In kidney transplant patients the use of the pill should be limited to the few patients with normal kidney function, normotension and no proteinuria, while alternative solutions need to be sought in all the other cases. Barrier methods are limited by their lower efficacy, except for ideal use, and in the case of choice of non-medicated intrauterine devices, attention to insertion procedures is warranted. No contraindications, except for spotting, exist for progestin-only birth control agents; however, due to potential pharmacologic interactions, the level of antirejection drugs (in particular calcineurin inhibitors, but also all the drugs metabolised in the cytochrome P450 pathway), should be carefully monitored.

While no formal contraindications exist for emergency progestin use, this treatment should not be routinely used in patients with occasional intercourse, and the risk of pharmacologic interactions should be borne in mind (in particular with calcineurin inhibitors).

Abortion is not, and should never be used as a means of birth control. It should be avoided whenever possible in all CKD women, in whom the physical and psychological balance between low fertility and unwanted pregnancy is particularly difficult. When a pregnancy needs to be interrupted, the limited evidence available on the lack of side effects of "medical" abortion should be balanced against the potential advantage of avoiding invasive procedures that risk further reducing fertility. These challenges are summarized in Fig. 1, depicting a treatment flow-chart based on the current knowledge on birth control in CKD patients.

Acknowledgements Editing of the manuscript and Open Access are provided by the Centre Hospitalier Le Mans.

Funding None.

\section{Compliance with ethical standards}

Conflict of interest The authors declare that they have no conflict of interest. 
Ethical approval This is a review paper, approved by all authors.

Open Access This article is licensed under a Creative Commons Attribution 4.0 International License, which permits use, sharing, adaptation, distribution and reproduction in any medium or format, as long as you give appropriate credit to the original author(s) and the source, provide a link to the Creative Commons licence, and indicate if changes were made. The images or other third party material in this article are included in the article's Creative Commons licence, unless indicated otherwise in a credit line to the material. If material is not included in the article's Creative Commons licence and your intended use is not permitted by statutory regulation or exceeds the permitted use, you will need to obtain permission directly from the copyright holder. To view a copy of this licence, visit http://creativecommons.org/licenses/by/4.0/.

\section{References}

1. Williams D, Davison J (2008) Chronic kidney disease in pregnancy. BMJ 336(7637):211-215

2. Piccoli GB, Alrukhaimi M, Liu ZH, Zakharova E, Levin A, World Kidney Day Steering Committee (2018) Women and kidney diseases: questions unanswered and answers unquestioned. Kidney Int Rep 3(2):225-235

3. Kattah AG, Garovic VD (2015) Pregnancy and lupus nephritis. Semin Nephrol 35(5):487-499

4. Moroni G, Ponticelli C (2016) Pregnancy in women with systemic lupus erythematosus (SLE). Eur J Intern Med. 32:7-12

5. Piccoli GB, Fassio F, Attini R, Parisi S, Biolcati M, Ferraresi M, Pagano A, Daidola G, Deagostini MC, Gaglioti P, Todros T (2012) Pregnancy in CKD: whom should we follow and why? Nephrol Dial Transplant. 27(Suppl 3):111-118

6. Kattah AG, Scantlebury DC, Agarwal S, Mielke MM, Rocca WA, Weaver AL, Vaughan LE, Miller VM, Weissgerber TL, White W, Garovic VD (2017) Preeclampsia and ESRD: the role of shared risk factors. Am J Kidney Dis 69(4):498-505

7. Filali Khattabi Z, Biolcati M, Fois A, Chatrenet A, Laroche D, Attini R, Cheve MT, Piccoli GB (2019) Chronic kidney disease in preeclamptic patients: not found unless searched for-Is a nephrology evaluation useful after an episode of preeclampsia? J Nephrol. 32(6):977-987

8. Tong A, Brown MA, Winkelmayer WC, Craig JC, Jesudason S (2015) Perspectives on pregnancy in women with CKD: a semistructured interview study. Am J Kidney Dis 66(6):951-961

9. Tong A, Jesudason S, Craig JC, Winkelmayer WC (2015) Perspectives on pregnancy in women with chronic kidney disease: systematic review of qualitative studies. Nephrol Dial Transplant 30(4):652-661

10. van Ek GF, Krouwel EM, Nicolai MPJ, Den Oudsten BL, Den Ouden MEM, Dieben SWM, Putter H, Pelger RCM, Elzevier HW (2017) What is the role of nephrologists and nurses of the dialysis department in providing fertility care to CKD patients? A questionnaire study among care providers. Int Urol Nephrol 49(7):1273-1285

11. van Ek GF, Krouwel EM, Nicolai MP, Bouwsma H, Ringers J, Putter H, Pelger RC, Elzevier HW (2015) Discussing sexual dysfunction with chronic kidney disease patients: practice patterns in the office of the nephrologist. J Sex Med. 12(12):2350-2363

12. Hendren EM, Reynolds ML, Mariani LH, Zee J, O'Shaughnessy MM, Oliverio AL, Moore NW, Hill-Callahan P, Rizk DV, Almanni S, Twombley KE, Herreshoff E, Nester CM, Hladunewich MA (2019) Confidence in women's health: a cross border survey of adult nephrologists. J Clin Med. 8(2):E176. https://doi. org $/ 10.3390 / \mathrm{jcm} 8020176$
13. Calic M, Grego K, Kersnic B, Jovanovic E, Svetlin M, Kandus A (2007) Education of transplanted women for prevention of unplanned pregnancy following kidney transplantation. J Ren Care 33(1): 17-19

14. Phillips PK, Saha S, Foley DP, Iruretagoyena JI, Said A (2019) Deficiencies in reproductive health counseling in liver transplant recipients. Clin Transplant 7:e13631

15. Carta P, Zanazzi M, Minetti EE (2015) Unplanned pregnancies in kidney transplanted patients treated with everolimus: three case reports. Transpl Int 28(3):370-372

16. Galappatthy P, Jayasinghe JDD, Paththinige SC, Sheriff RMH, Wijayaratne LS (2017) Pregnancy outcomes and contraceptive use in patients with systemic lupus Erythematosus, rheumatoid arthritis and women without a chronic illness: a comparative study. Int J Rheum Dis. 20(6):746-754

17. Burgner A, Hladunewich MA (2019) Women's reproductive health for the nephrologist. Am J Kidney Dis. pii: S0272-6386(19)30737-1

18. Wiles KS, Nelson-Piercy C, Bramham K (2018) Reproductive health and pregnancy in women with chronic kidney disease. Nat Rev Nephrol 14(3):165-184

19. Ahmed SB, Vitek WS, Holley JL (2017) Fertility, contraception, and novel reproductive technologies in chronic kidney disease. Semin Nephrol 37(4):327-336

20. Yousif ME, Bridson JM, Halawa A (2016) Contraception after kidney transplantation, from myth to reality: a comprehensive review of the current evidence. Exp Clin Transplant 14(3):252-258

21. Josephson MA, McKay DB (2013) Women and transplantation: fertility, sexuality, pregnancy, contraception. Adv Chronic Kidney Dis. 20(5):433-440

22. Gourdy P (2013) Diabetes and oral contraception. Best Pract Res Clin Endocrinol Metab 27(1):67-76

23. Lazzaroni MG, Dall'Ara F, Fredi M, Nalli C, Reggia R, Lojacono A, Ramazzotto F, Zatti S, Andreoli L, Tincani A (2016) A comprehensive review of the clinical approach to pregnancy and systemic lupus erythematosus. J Autoimmun 74:106-117

24. Cabiddu G, Spotti D, Gernone G, Santoro D, Moroni G, Gregorini G, Giacchino F, Attini R, Limardo M, Gammaro L, Todros T, Piccoli GB, Kidney and Pregnancy Study Group of the Italian Society of Nephrology (2018) A best-practice position statement on pregnancy after kidney transplantation: focusing on the unsolved questions. The Kidney and Pregnancy Study Group of the Italian Society of Nephrology. J Nephrol 31(5):665-681

25. Piccoli GB, Cabiddu G, Castellino S, Gernone G, Santoro D, Moroni G, Spotti D, Giacchino F, Attini R, Limardo M, Maxia S, Fois A, Gammaro L, Todros T, Kidney and Pregnancy Study Group of Italian Society of Nephrology (2017) A best practice position statement on the role of the nephrologist in the prevention and follow-up of preeclampsia: the Italian study group on kidney and pregnancy. J Nephrol. 30(3):307-317

26. Cabiddu G, Castellino S, Gernone G, Santoro D, Moroni G, Giannattasio M, Gregorini G, Giacchino F, Attini R, Loi V, Limardo M, Gammaro L, Todros T, Piccoli GB (2016) A best practice position statement on pregnancy in chronic kidney disease: the Italian Study Group on Kidney and Pregnancy. J Nephrol. 29(3):277-303

27. Cabiddu G, Castellino S, Gernone G, Santoro D, Giacchino F, Credendino O, Daidone G, Gregorini G, Moroni G, Attini R, Minelli F, Manisco G, Todros T, Piccoli GB, Kidney and Pregnancy Study Group of Italian Society of Nephrology (2015) Best practices on pregnancy on dialysis: the Italian Study Group on Kidney and Pregnancy. J Nephrol. 28(3):279-288

28. https://apps.who.int/iris/bitstream/handle/10665/181468/97892 41549158_eng.pdf?sequence=9. Accessed 20 Nov 2019 
29. Trussell J (2007) Contraceptive efficacy. In: Hatcher RA, Trussell J, Nelson AL, Cates W, Stewart F, Kowal D (eds) Contraceptive technology, 19th edn. Ardent Media, New York, pp 747-826

30. https://www.prb.org/2019-family-planning-data-sheet-highlights -family-planning-method-use-around-the-world/. Accessed 20 Nov 2019

31. https://www.ema.europa.eu/en/find-medicine/human-medicines/ referrals/combined-hormonal-contraceptives. Accessed $20 \mathrm{Nov}$ 2019

32. Oedingen C, Scholz S, Razum O (2018) Systematic review and meta-analysis of the association of combined oral contraceptives on the risk of venous thromboembolism: the role of the progestogen type and oestrogen dose. Thromb Res 165:68-78

33. Van Hylckama Vlieg A, Helmerhorst FM, Vandenbroucke JP, Doggen CJ, Rosendaal FR (2009) The venous thrombotic risk of oral contraceptives, effects of oestrogen dose and progestogen type: results of the MEGA case-control study. BMJ 13(339):b2921

34. Tepper NK, Dragoman MV, Gaffield ME, Curtis KM (2017) Nonoral combined hormonal contraceptives and thromboembolism: a systematic review. Contraception 95(2):130-139

35. Jick SS, Hernandez RK (2011) Risk of non-fatal venous thromboembolism in women using oral contraceptives containing drospirenone compared with women using oral contraceptives containing levonorgestrel: case-control study using United States claims data. BMJ 21(342):d2151

36. Szarewski A, Mansour D (2011) Study subject to unmeasured confounders and biases. BMJ 31(342):d3349. https://doi. org/10.1136/bmj.d3349

37. Chasan-Taber L, Willett WC, Manson JE et al (1996) Prospective study of oral contraceptives and hypertension among women in the United States. Circulation. 94:483-489

38. Liu H, Yao J, Wang W, Zhang D (2017) Association between duration of oral contraceptive use and risk of hypertension: a meta-analysis. J Clin Hypertens (Greenwich). 19(10):1032-1041. https://doi.org/10.1111/jch.13042 (Epub 2017 Jun 13)

39. August $P$ (2013) Hypertension in women. Adv Chronic Kidney Dis. 20(5):396-401. https://doi.org/10.1053/j.ackd.2013.07.002

40. Atthobari J, Gansevoort RT, Visser ST, de Jong PE, de Jong van den Berg LT, PREVEND Study Group (2007) The impact of hormonal contraceptives on blood pressure, urinary albumin excretion and glomerular filtration rate. $\mathrm{Br} \mathrm{J}$ Clin Pharmacol. 63(2):224-231

41. Ahmed SB, Kang AK, Burns KD et al (2004) Effects of oral contraceptive use on the renal and systemic vascular response to angiotensin II infusion. JAmSocNephrol. 15:780-786

42. Ahmed B, Hovind P, Parving HH et al (2005) Oral contraceptives, angiotensin-dependent renal vasoconstriction, and risk of diabetic nephropathy. Diabetes Care. 28:1988-1994

43. Monster TB, Janssen WM, and Prevention of Renal and Vascular End Stage Disease Study Group (2001) Oral contraceptive use and hormone replacement therapy are associated with microalbuminuria. ArchIntern Med. 161:2000-2005

44. Kang AK, Duncan JA, Cattran DC, Floras JS, Lai V, Scholey JW, Miller JA (2001) Effect of oral contraceptives on the renin angiotensin system and renal function. Am J Physiol Regul Integr Comp Physiol 280(3):R807-R813

45. Ribstein J, Halimi JM, du Cailar G, Mimran A (1999) Renal characteristics and effect of angiotensin suppression in oral contraceptive users. Hypertension 33(1):90-95

46. Schürmann R, Blode H, Benda N, Cronin M, Küfner A (2006) Effect of drospirenone on serum potassium and drospirenone pharmacokinetics in women with normal or impaired renal function. J Clin Pharmacol 46(8):867-875

47. Peng Y, Wang X, Feng H, Yan G (2017) Is oral contraceptive use associated with an increased risk of cervical cancer?
An evidence-based meta-analysis. J Obstet Gynaecol Res. 43(5):913-922

48. Oh HY, Kim MK, Seo S, Lee J (2016) Association of combined tobacco smoking and oral contraceptive use with cervical intraepithelial neoplasia 2 or 3 in Korean women. J Epidemiol 26:22-29

49. Urban M, Banks E, Egger S et al (2012) Injectable and oral contraceptive use and cancers of the breast, cervix, ovary, and endometrium in black South African women: case-control study. PLoS Med 9:e1001182

50. Nojomi M, Modaresgilani M, Mozafari N, Erfany A (2008) Cervical cancer and duration of using hormonal contraceptives. Asia Pac J Clin Oncol 4:107-112

51. Vanakankovit N, Taneepanichskul S (2008) Effect of oral contraceptives on risk of cervical cancer. J Med Assoc Thai 91:7-12

52. Green J, Berrington DGA, Sweetland S et al (2003) Risk factors for adenocarcinoma and squamous cell carcinoma of the cervix in women aged 20-44 years: The UK National Case-Control Study of Cervical Cancer. Br J Cancer 89:2078-2086

53. Shapiro S, Rosenberg L, Hoffman M et al (2003) Risk of invasive cancer of the cervix in relation to the use of injectable progestogen contraceptives and combined oestrogen/progestogen oral contraceptives (South Africa). Cancer Causes Control 14:485-495

54. Berrington A, Jha P, Peto J, Green J, Hermon C (2002) Oral contraceptives and cervical cancer. Lancet 360:410

55. Smith JS, Green J, Berrington DGA et al (2003) Cervical cancer and use of hormonal contraceptives: a systematic review. Lancet 361:1159-1167

56. Gierisch JM, Coeytaux RR, Urrutia RP et al (2013) Oral contraceptive use and risk of breast, cervical, colorectal, and endometrial cancers: a systematic review. Cancer Epidemiol Biomark Prev 22:1931-1943

57. Iodice S, Barile M, Rotmensz N, Feroce I, Bonanni B, Radice P, Bernard L, Maisonneuve P, Gandini S (2010) Oral contraceptive use and breast or ovarian cancer risk in BRCA $1 / 2$ carriers: a meta-analysis. Eur J Cancer 46(12):2275-2284

58. Dolle JM, Daling JR, White E et al (2009) Risk factors for triple-negative breast cancer in women under the age of 45 years. Cancer Epidemiol Biomark Prev 18(4):1157-1166

59. Vanidassane I, Gogia A, Kumar L (2018) Contemporary hormonal contraceptives and breast cancer risk: what do we learn? Natl Med J India. 31(3):156-157

60. Del Pup L, Codacci-Pisanelli G, Peccatori F (2019) Breast cancer risk of hormonal contraception: counselling considering new evidence. Crit Rev Oncol Hematol 137:123-130

61. Barriga P, Vanhauwaert P, Porcile A (2019) Hormonal contraception and risk of breast cancer: a critical look. Gynecol Endocrinol 35(6):460-462

62. Serfaty D (2019) Update on the contraceptive contraindications. J Gynecol Obstet Hum Reprod. 48(5):297-307. https:// doi.org/10.1016/j.jogoh.2019.02.006 (Epub 2019 Feb 20)

63. Bitzer J (2019) Overview of perimenopausal contraception. Climacteric 22(1):44-50

64. Nagykálnai T, Landherr L (2018) Oral contraception and the risk of breast cancer. Review of the literature. Magy Onkol. 62(4):258-263

65. Amat L, Bulach A, Leclercq M, Mesrine S, Scheffler F, Sperandeo D, Scheffler M (2018) Additional non-contraceptive effects of contraception: CNGOF Contraception Guidelines. Gynecol Obstet Fertil Senol. 46(12):883-888

66. Pragout D, Laurence V, Baffet H, Raccah-Tebeka B, Rousset-Jablonski C (2018) Contraception and cancer: CNGOF contraception guidelines. Gynecol Obstet Fertil Senol 46(12):834-844 
67. Pasanisi P, Bruno E (2018) Breast cancer in BRCA mutations carriers: is it time forn a "lifestyle" primary prevention? Epidemiol Prev 42(5-6):369-371

68. Schneyer R, Lerma K (2018) Health outcomes associated with use of hormonal contraception: breast cancer. Curr Opin Obstet Gynecol 30(6):414-418

69. Westhoff CL, Pike MC (2018) Hormonal contraception and breast cancer. Contraception 98(3):171-173

70. Baum JK, Bookstein JJ, Holtz F et al (1973) Possible association between benign hepatomas and oral contraceptives. Lancet 2:926-929

71. Giannitrapani L, Soresi M, Spada E et al (2006) Sex hormones and risk of liver tumor. Ann N Y Acad Sci 1089:228-236

72. Klatskin G (1977) Hepatic tumors: possible relationship to use of oral contraceptives. Gastroenterology 73:386-394

73. Gemer O, Moscovici O, Ben-Horin CL et al (2004) Oral contraceptives and liver hemangioma: a case-control study. Acta Obstet. Gynecol. Scand. 83:1199-1201

74. Glinkova V, Shevah O, Boaz M et al (2004) Hepatic haemangiomas: possible association with female sex hormones. Gut 53:1352-1355

75. Beral V, Doll R, Hermon C, Peto R, Reeves G (2008) Ovarian cancer and oral contraceptives: collaborative reanalysis of data from 45 epidemiological studies including 23,257 women with ovarian cancer and 87,303 controls. Lancet 371:303-314

76. Kim M, Suh DH, Lee KH, Eom KY, Toftdahl NG, Mirza MR, Kim JW (2019) Major clinical research advances in gynecologic cancer in 2018. J Gynecol Oncol. 30(2):e18

77. La Vecchia C (2017) Ovarian cancer: epidemiology and risk factors. Eur J Cancer Prev. 26(1):55-62 (Review)

78. Iversen L, Fielding S, Lidegaard Ø, Mørch LS, Skovlund CW, Hannaford PC (2018) Association between contemporary hormonal contraception and ovarian cancer in women of reproductive age in Denmark: prospective, nationwide cohort study. BMJ 26(362):k3609

79. Koushik A, Grundy A, Abrahamowicz M, Arseneau J, Gilbert L, Gotlieb WH, Lacaille J, Mes-Masson AM, Parent MÉ, Provencher DM, Richardson L, Siemiatycki J (2017) Hormonal and reproductive factors and the risk of ovarian cancer. Cancer Causes Control 28(5):393-403

80. Lopez LM, Grimes DA, Gallo MF, Stockton LL, Schulz KF (2013) Skin patch and vaginal ring versus combined oral contraceptives for contraception. Cochrane Database Syst Rev. 4:CD003552

81. Paternoster DM, Riboni F, Bertolino M, Garofalo G, Lazzarich E, Surico N, Stratta P (2010) The contraceptive vaginal ring in women with renal and liver transplantation: analysis of preliminary results. Transplant Proc. 42(4):1162-1165

82. Saudi J (2008) Pregnancy and contraceptive issues in renal transplant recipients. Kidney Dis Transpl 19:165

83. Pietrzak B, Bobrowska K, Jabiry-Zieniewicz Z et al (2007) Oral and transdermal hormonal contraception in women after kidney transplantation. Transplant Proc 39:2759

84. Vickery Z, Madden T, Zhao Q, Secura GM, Allsworth JE, Peipert JF (2013) Weight change at 12 months in users of three progestin-only contraceptive methods. Contraception. 88(4):503-508

85. Lopez LM, Ramesh S, Chen M, Edelman A, Otterness C, Trussell J, Helmerhorst FM (2016) Progestin-only contraceptives: effects on weight. Cochrane Database Syst Rev. 8:CD008815

86. Gallo MF, Legardy-Williams J, Hylton-Kong T, Rattray C, Kourtis AP, Jamieson DJ, Steiner MJ (2016) Association of progestin contraceptive implant and weight gain. Obstet Gynecol 127(3):573-576

87. Yancey JR, Raleigh M (2014) Progestin-only contraceptives: effects on weight. Am Fam Physician 89(9):715-716
88. Silva Dos Santos PN, Madden T, Omvig K, Peipert JF (2017) Changes in body composition in women using long-acting reversible contraception. Contraception. 95(4):382-389

89. Sánchez-Guerrero J, Uribe AG, Jiménez-Santana L, MestanzaPeralta M, Lara-Reyes P, Seuc AH, Cravioto MD (2005) A trial of contraceptive methods in women with systemic lupus erythematosus. N Engl J Med 353(24):2539-2549

90. FSRH (RCOG) Clinical Guideline: Progestogen-only pill, 2019. https://www.fsrh.org/standards-and-guidance/documents/cecceu-guidance-pop-mar-2015/. Accessed 20 Nov 2019

91. Tepper NK, Whiteman MK, Marchbanks PA, James AH, Curtis KM (2016) Progestin-only contraception and thromboembolism: a systematic review. Contraception 94(6):678-700

92. Gray B, Floyd S, James AH (2018) Contraceptive management for women who are at high risk of thrombosis. Clin Obstet Gynecol 61(2):243-249

93. Sitruk-Ware R (2016) Hormonal contraception and thrombosis. Fertil Steril 106(6):1289-1294

94. Mantha S, Karp R, Raghavan V, Terrin N, Bauer KA, Zwicker JI (2012) Assessing the risk of venous thromboembolic events in women taking progestin-only contraception: a meta-analysis. BMJ 7(345):e4944

95. Sammaritano LR (2017) Contraception in patients with rheumatic disease. Rheum Dis Clin North Am 43(2):173-188. https ://doi.org/10.1016/j.rdc.2016.12.001

96. Romano ME, Braun-Courville DK (2019) Assessing weight status in adolescent and young adult users of the etonogestrel contraceptive implant. J Pediatr Adolesc Gynecol 32(4):409-414

97. Villas-Boas J, Vilodre LC, Malerba H, Pontremoli Salcedo M, Foresti Jiménez M, El Beitune P (2016) Metabolic safety of the etonogestrel contraceptive implant in healthy women over a 3-year period. Eur J Obstet Gynecol Reprod Biol 202:51-54

98. Bahamondes L, Brache V, Meirik O, Ali M, Habib N, Landoulsi S, WHO Study Group on Contraceptive Implants for Women (2015) A 3-year multicentre randomized controlled trial of etonogestrel- and levonorgestrel-releasing contraceptive implants, with non-randomized matched copper-intrauterine device controls. Hum Reprod. 30(11):2527-2538

99. Modesto W, Dal Ava N, Monteiro I, Bahamondes L (2015) Body composition and bone mineral density in users of the etonogestrel-releasing contraceptive implant. Arch Gynecol Obstet 292(6): 1387-1391

100. Sarfati J, de Vernejoul MC (2009) Impact of combined and progestogen-only contraceptives on bone mineral density. Joint Bone Spine. 76(2):134-138

101. Lopez LM, Grimes DA, Schulz KF, Curtis KM, Chen M (2014) Steroidal contraceptives: effect on bone fractures in women. Cochrane Database Syst Rev. 6:33

102. Pongsatha S, Ekmahachai M, Suntornlimsiri N, Morakote N, Chaovisitsaree $S$ (2010) Bone mineral density in women using the subdermal contraceptive implant Implanon for at least 2 years. Int J Gynaecol Obstet 109(3):223-225

103. Draper B, Morroni C, Hoffman M, Smit J, Beksinska M, Hapgood J, van der Merwe L (2006) Depot medroxyprogesterone versus Norethisterone oenanthate for long-acting progestogenic contraception. Cochrane Systematic Rev 19(3):CD005214

104. Neri M, Piras B, Paoletti AM, Vallerino V, Corda V, Ronchetti C, Taccori V, Pilloni M, Zedda P, Capobianco G, Dessole S, Melis GB, Mais V (2018) Long-acting reversible contraception (LARC) with the intrauterine system with levonorgestrel (6 mcg/day): observational study on the acceptability, quality of life, and sexuality in Italian women. Gynecol Endocrinol 34(6):532-535

105. Foran T, Butcher BE, Kovacs G, Bateson D, O'Connor V (2018) Safety of insertion of the copper IUD and LNG-IUS 
in nulliparous women: a systematic review. Eur J Contracept Reprod Health Care. 23(5):379-386

106. Andreoli L, Bertsias GK, Agmon-Levin N, Brown S, Cervera $\mathrm{R}$ et al (2017) EULAR recommendations for women's health and the management of family planning, assisted reproduction, pregnancy and menopause in patients with systemic lupus erythematosus and/or antiphospholipid syndrome. Ann Rheum Dis 76(3):476-485

107. FSRH (RCOG) Clinical Guideline: Intrauterine Contraception 2019. https://www.fsrh.org/standards-and-guidance/documents/ ceuguidanceintrauterinecontraception/. Accessed 20 Nov 2019

108. Li C, Zhao WH, Zhu Q, Cao SJ, Ping H, Xi X, Qin GJ, Yan MX, Zhang D, Qiu J, Zhang J (2015) Risk factors for ectopic pregnancy: a multi-center case-control study. BMC Pregnancy Childbirth 22(15):187

109. Gaskins AJ, Missmer SA, Rich-Edwards JW, Williams PL, Souter I, Chavarro JE (2018) Demographic, lifestyle, and reproductive risk factors for ectopic pregnancy. Fertil Steril 110(7):13281337. https://doi.org/10.1016/j.fertnstert.2018.08.022

110. Escobar-Padilla B, Perez-López CA, Martínez-Puon H (2017) Risk factors and clinical features of ectopic pregnancy. Rev Med Inst Mex Seguro Soc. 55(3):278-285

111. Xiong X, Buekens P, Wollast E (1995) IUD use and the risk of ectopic pregnancy: a meta-analysis of case-control studies. Contraception. 52(1):23-34

112. Stephen-Searle E (2014) The intrauterine device and the intrauterine system. Best Pract Res Clin Obstet Gynaecol. 28(6):807-824

113. Lohr PA, Lyus R, Prager S (2017) Use of intrauterine devices in nulliparous women. Contraception. 95(6):529-537

114. Sonalkar S, Kapp N (2015) Intrauterine device insertion in the postpartum period: a systematic review. Eur J Contracept Reprod Health Care 20(1):4-18

115. Sufrin CB, Postlethwaite D, Armstrong MA, Merchant M, Wendt JM, Steinauer JE (2012) Neisseria gonorrhea and Chlamydia trachomatis screening at intrauterine device insertion and pelvic inflammatory disease. Obstet Gynecol 120(6):1314-1321

116. Farley TM, Rosenberg MJ, Rowe PJ, Chen JH, Meirik O (1992) Intrauterine devices and pelvic inflammatory disease: an international perspective. Lancet 339(8796):785-788

117. Toivonen J, Luukkainen T, Allonen H (1991) Protective effect of intrauterine release of levonorgestrel on pelvic infection: three years' experience of levonorgestrel- and copper-releasing intrauterine devices. Obstet Gynecol 77:261-264

118. Sivin I, Stern J (1994) Health during prolonged use of levonorgestrel $20 \mathrm{mg} / \mathrm{d}$ and the Copper TCu 380Ag intrauterine contraceptive devices: a multicenter study. Fertil Steril 61:70-77

119. Sheppard BL (1987) Endometrial morphological changes in IUD users: a review. Contraception. 36(1):1-10

120. Stringer EM, Kaseba C, Levy J, Sinkala M, Goldenberg RL, Chi BH, Matongo I, Vermund SH, Mwanahamuntu M, Stringer JS (2007) A randomized trial of the intrauterine contraceptive device vs hormonal contraception in women who are infected with the human immunodeficiency virus. Am J Obstet Gynecol 197(2):144.e1-144.e8

121. Flamigni C, Pompili A - Contraccezione, L'Asino d'oro Ed, 2011, www.lasinodoroedizioni.it. Accessed 20 Nov 2019
122. Fihn SD, Boyko EJ, Chen CL, Normand EH, Yarbro P, Scholes D (1998) Arch; Use of spermicide-coated condoms and other risk factors for urinary tract infection caused by Staphylococcus saprophyticus. Intern Med 158(3):281-287

123. Fihn SD, Latham RH, Roberts P, Running K, Stamm WE (1985) Association between diaphragm use and urinary tract infection. JAMA. 254:240-245

124. Foxman B, Frerichs RR (1985) Epidemiology of urinary tract infection, I: diaphragm use and sexual intercourse. Am J Public Health. 75:1308-1313

125. Peddie BA, Bishop V, Blake EE, Gorrie SI, Bailey RR, Edwards D (1986) Association between diaphragm use and asymptomatic bacteriuria. Aust N Z J Obstet Gynaecol. 26:225-227

126. Percival-Smith R, Bartlett KH, Chow AW (1983) Vaginal colonization of Escherichia coli and its relation to contraceptive methods. Contraception. 2:7497

127. Hooton TM, Scholes D, Hughes JP, Winter C, Roberts PL, Stapleton AE, Stergachis A, Stamm WE (1996) A prospective study of risk factors for symptomatic urinary tract infection in young women. N Engl J Med 335(7):468-474

128. Mittal S (2016) Emergency contraception: which is the best? Minerva Ginecol 68(6):687-699 (Epub 2016 Apr 15)

129. Practice Bulletin No 152 (2015) Emergency contraception. Obstet Gynecol 126(3):e1-e11

130. Art A (2017) Emergency Contraception. J Obstet Gynecol Neonatal Nurs. 46(6):886-888 (Emergency Contraception. Nurs Womens Health. 2017 21(6):506-508)

131. Fok WK, Blumenthal PD (2016) Update on emergency contraception. Curr Opin Obstet Gynecol 28(6):522-529

132. Black KI, Hussainy SY (2017) Emergency contraception: oral and intrauterine options. Aust Fam Physician 46(10):722-726

133. Nie JB (2011) Non-medical sex-selective abortion in China: ethical and public policy issues in the context of 40 million missing females. Br Med Bull 98:7-20

134. Diamond-Smith N, Saikia N, Bishai D, Canudas-Romo V (2019) What has contributed to improvements in the child sex ratio in select districts of India? A decomposition of the sex ratio at birth and child mortality. J Biosoc Sci 22:1-10

135. https://reproductiverights.org/worldabortionlaws?country. Accessed 20 Nov 2019

136. Boim MA, Draibe SA, Ramos OL, Ajzen H, Ulmann A, Schor N (1994) Glomerular hemodynamics during abortion induced by RU 486 and sepsis in rats. Braz J Med Biol Res 27(6):1431-1444

137. Mittal S, Aggarwal P (2011) Medical abortion in women with impaired renal function. Int J Gynaecol Obstet 114:76-77

138. Say L, Kulier R, Gülmezoglu M, Campana A (2005) Medical versus surgical methods for first trimester termination of pregnancy. Cochrane Database Syst Rev. 1:CD003037

Publisher's Note Springer Nature remains neutral with regard to jurisdictional claims in published maps and institutional affiliations. 